\title{
El gobierno municipal, del voluntarismo a la gobernanza
}

\author{
Albert Calderó* \\ Manuel Zafra*
}

\section{El gobierno municipal está reunido}

Dieciocho horas de un lunes. Un grupo municipal de gobierno delibera sobre las iniciativas políticas que llevará al próximo pleno, la reunión tiene lugar a estas horas porque varios concejales del equipo trabajan y resulta imposible convocarla antes, durará hasta las veintidós. A la altura de las veinte cuarenta y cinco interviene el concejal de urbanismo, se ha incorporado un poco más tarde, es médico y ha debido atender a un paciente. Como desconoce el vocabulario específico de la materia ha preparado cuidadosamente la propuesta, lleva varios días estudiando los informes técnicos e intercambiando impresiones con el arquitecto.

A lo largo de veinte minutos, el concejal expone el plan de reforma en un barrio de la ciudad, sus compañeros escuchan entre sorprendidos e indiferentes el manejo de los términos urbanísticos, cuando finaliza, pregunta las dudas que la iniciativa merece al equipo, una joven concejala, nueva en el cargo, responsable del área de cultura y deportes, pide aclaración sobre las eventuales repercusiones del proyecto en el polideportivo, el concejal hace un gesto de negación y acto seguido, solicita la aprobación que obtiene el asentimiento deferente del resto del equi- po. El alcalde da por concluida la deliberación y apremia para la discusión del punto próximo. Son las veintiuna treinta y quedan varias intervenciones.

\section{El arquitecto municipal polivalente}

En otro ayuntamiento. Las once de la mañana de cualquier día laborable. El arquitecto municipal recibe la visita del concejal de obras, quiere saber el estado del proyecto sobre alumbrado público en una calle de la ciudad. El arquitecto pide disculpas por el retraso, la remodelación del teatro municipal requiere en este momento toda su dedicación. Al cabo de un rato suena el teléfono, el concejal de cultura le recuerda la urgencia de la remodelación en el teatro. Es cierto, pero el concejal de urbanismo ha llamado apremiando los informes de licencias y no dispone de tiempo suficiente para atender tantas peticiones simultáneas. El concejal de urbanismo le advierte de la premura en contar con las licencias. El arquitecto, un poco molesto, le hace saber que anda muy ocupado en el proyecto de alumbrado y en el teatro. 


\section{Así es el gobierno y la dirección en la mayoría de los ayuntamientos}

Es así. En la mayoría de los ayuntamientos españoles la labor de gobierno consiste en el desempeño voluntarista de responsabilidades políticas desde un casi completo desconocimiento, que intenta compensarse con una dedicación heroica y con unos métodos de gobierno de una patética inadecuación a las necesidades y exigencias de la democracia del siglo XXI.

A los que desconozcan el funcionamiento interno de los Ayuntamientos actuales las dos anécdotas les parecerán fantasías surrealistas propias de Buñuel. A los que conocen la realidad les parece, en general, una pintura muy realista. No es la primera vez que contamos estas anécdotas: solemos utilizarlas en los seminarios que a menudo impartimos para alcaldes y concejales. Nuestros asistentes reconocen en estas narraciones escenas familiares con frecuentes gestos de asentimiento.

El propósito de nuestro trabajo es ofrecer claves para mejorar la dirección política de los ayuntamientos. Creemos que ésta es la directriz crucial de una estrategia que pretenda mejorar nuestro sistema político local, enmarcando el tema en la calidad de la representación.

Hoy es habitual declarar el agotamiento de la democracia representativa y abogar por formas de participación ciudadana como única o, al menos, mejor camino para mejorar la calidad de la democracia local. Nosotros no negamos los beneficios de la participación pero sostenemos que tendrá un alcance limitado si descuidamos la importancia de la representación. Procedemos así invirtiendo los términos del debate: lo habitual en la literatura politológica es buscar formas de innovación democrática como los jurados ciudadanos o los presupuestos participativos; nosotros, en cambio, pretendemos reforzar la representación contribuyendo a un mejor entendimiento de la política local.

No obstante, la nuestra no es sólo una propuesta del lado de los gobernantes, también lo es del lado de los gobernados porque la calidad de la representación obliga a plantear la piedra angular del concepto: la controversia entre el mandato de los representados y la independencia de los representantes.

Concebida en estas coordenadas, la organización del gobierno local ha de contemplarse dentro de la teoría de la democracia. Sería insuficiente reducir la cuestión a un mero reajuste de las concejalías para hacer del equipo de gobierno una organización eficiente, el objetivo es más elevado: hacer de la relación gobernantes-gobernados el eje de la política local.

\section{El modelo ministerial: una forma de gobierno local manifiestamente mejorable}

La primera anécdota refleja las formas de trabajo habituales de la mayoría de equipos de gobierno de los ayuntamientos españoles de tamaño medio, de diez mil a un millón de habitantes. En ellos el Alcalde, nada más tomar posesión reparte delegaciones, es decir, reparte sus atribuciones como jefe de la administración municipal, a todos los concejales electos de su candidatura, estructurando una especie de consejo de ministros local. Cada concejal recibe un "trozo de ayuntamiento" que administrar. Cada concejal se convierte en una especie de ministro local de cultura, o deportes, o hacienda, o urbanismo, o sanidad. Cada concejal, a partir de ese momento, en teoría, debe dirigir a los funcionarios que se ocupan de las materias de su competencia, debe recibir a los ciudadanos que quieren tratar de esos asuntos, debe ser un negociador de sus temas ante las administraciones superiores, debe definir las políticas de su campo, etc. Igual que un ministro, es un responsable integral de la temática municipal que le ha correspondido.

Claro que las diferencias entre un ministro y un concejal electo son bastante considerables. En España un Presidente del Gobierno puede elegir a sus ministros no ya entre los diputados de su partido (que ya sería un gran campo donde elegir, pues un partido ganador de las elecciones generales dispone al menos de 160 o 170 diputados), no ya entre los cientos de miles de militantes de su partido, sino entre todos los españoles mayores de edad. Así, elegir buenos ministros es factible.

Pero según el sistema de gobierno imperante hoy en España ${ }^{1}$ un alcalde debe repartir todos los "ministerios" de su ayuntamiento entre todos los miembros electos de su lista. Debe encontrar en ese pequeño grupo de diez, doce, catorce personas a un buen directivo de los técnicos y administrativos de urbanismo, que sepa mucho de urbanismo, que sea además un gran negociador, que sea capaz de idear las políticas urbanísticas y sea un buen relaciones públicas para atender sobre ese tema a los vecinos, y a los promotores, y a los arquitectos, ...y a los periodistas. $Y$ además debe encontrar también un personaje de parecidas cualidades en el campo de la hacienda, y otro en el campo de la sanidad, y otro en el campo de los servicios sociales, y así sucesivamente hasta agotar el amplio y variado temario de la política municipal.

Claro, es completamente imposible que una lista electoral local albergue a diez, doce, catorce especialistas en las diez, doce, catorce temáticas sectoriales municipales. Lo que sucede siempre es que casi todos ellos son unos perfectos ignorantes de sus com- 
petencias, y que confían en algún milagro que les otorgue la inspiración necesaria para no meter la pata.

¿Cómo es posible que tamaña aberración sea considerada en general, por parte de todos los partidos políticos, el sistema idóneo para gobernar los ayuntamientos?

Todo es culpa de la inercia. Han pervivido unas formas de organizar el gobierno surgidas en un contexto que ha desaparecido, y la inercia las mantiene con manifiesto quebranto del buen gobierno local.

En 1979, al inicio de la democracia local, los municipios arrastraban un atraso secular, agravado por la incertidumbre de la transición: en los cuatro años que median entre la muerte de Franco y las primeras elecciones municipales, la política local estuvo varada en la provisionalidad.

Todo estaba por hacer. Los servicios públicos más elementales: agua, alumbrado, pavimentación... presentaban unos niveles mínimos. Esta evidencia de las necesidades propició que los ayuntamientos democráticos nacieran como organizaciones de rendimiento en un contexto simple y previsible. Llamaremos a estas organizaciones de rendimiento modelo ministerial. El gobierno se divide en áreas dirigidas por un concejal según el principio de división del trabajo pero, como señala H. MinTZBERG ${ }^{2}$, una organización es una simultaneidad problemática entre la división del trabajo y la posterior coordinación para facilitar visión de conjunto.

La división del trabajo empuja a la organización con una fuerza centrífuga, la coordinación, en cambio, intenta neutralizar la fragmentación con una fuerza centrípeta. Este campo de fuerzas lleva a la organización en direcciones encontradas, no son complementarias, pueden llegar a serlo pero no se puede descontar que la conciliación tenga lugar de forma espontánea.

Enumeramos a continuación los males del modelo ministerial siguiendo la tensión entre ambos principios organizativos. Antes hemos de aludir a una variante propia del gobierno local provocada por el marco legal que multiplica el número de áreas y, por tanto, eleva los costes de coordinación. A diferencia de otros niveles de gobierno como el nacional o el autonómico, en el gobierno local quienes integran el equipo de gobierno han de ser elegidos, el alcalde no puede nombrar concejal a alguien que no se haya presentado a las elecciones. Esta restricción hace que los componentes de una lista con expectativas de ganar tengan la seguridad de asumir responsabilidades de gobierno con retribución y dedicación exclusiva.

No es de extrañar que el número de áreas sean tan extenso como aspirantes. La fragmentación que genera este fenómeno encarece los costes de coordinación y convierte al alcalde en árbitro de las disputas entre concejalías. Aumenta la tentación de elevar al alcalde cualquier situación problemática de rivalidad entre áreas con el efecto indeseable de emplear más tiempo en resolver los conflictos internos que en gobernar. El alcalde carece de argumentos para dirimir las diferencias porque desconoce la realidad de donde surgen, decidirá intuitivamente $y$, con toda probabilidad, acentuará el mal.

Esta saturación en el vértice congestiona la dirección política. Todas las debilidades del modelo ministerial nacen de la descoordinación y, a su vez, la descoordinación de un déficit de deliberación colegiada y de un verdadero esfuerzo conjunto que debería ser previo al impulso de las políticas, pero que, paradójicamente, tiene lugar una vez puestas en marcha las iniciativas.

El caso del concejal de urbanismo expresa cabalmente la baja calidad del tiempo dedicado a la deliberación. Las reuniones de la comisión de gobierno en no pocas ocasiones suponen una "socialización de la incertidumbre" cuando un concejal siente inseguridad ante un asunto controvertido y solicita la anuencia del resto de los miembros del gobierno para compartir los riesgos de la medida. Sin embargo, la solicitud de ayuda resulta inútil porque nadie quiere asumir responsabilidad sin haber intervenido ni disponer de información suficiente.

Quizás la consecuencia más inquietante de este tiempo marginal dedicado a la deliberación, unido a la bisoñez de los concejales y a la inevitable rivalidad entre áreas, sea la virtual captura de los miembros del gobierno local por los grupos bien organizados del municipio hasta el punto de que el concejal de turno acaba erigido en defensor de esos intereses ante los restantes miembros del equipo. Al carecer de estrategia para discriminar entre diferentes políticas, las prioridades no se fijan atendiendo a la relevancia de un problema sino a la habilidad de cada concejal para argumentar la oportunidad de sus peticiones. No sería extraño que el concejal con los argumentos más persuasivos estuviera aleccionado por uno de esos grupos de presión.

No debemos dejarnos ganar por el prejuicio de ver en los grupos de interés los portadores de pretensiones particulares e inadmisibles pero tampoco podemos olvidar que son los asuntos más específicos los que superan las dificultades de la acción colectiva. Según M. OLSON ${ }^{3}$, cuando un problema afecta a un colectivo de gente muy amplio difícilmente lo movilizará; por el contrario si los beneficios o los perjuicios recaen sobre un grupo pequeño no tardará en reaccionar para oponerse o apoyar la política. De ahí que los intereses mejor organizados puedan ser los menos generalizables. Si un gobierno local no está en condiciones de examinar estas situaciones acabará cediendo a la estrategia articulada por los grupos.

Como luego tendremos ocasión de analizar, los grupos de interés, las asociaciones de vecinos, las empresas o los sindicatos forman parte de una red que debe ser gobernada pero para sacar lo más provechoso de la red es necesario que el gobierno lidere la articulación de los diferentes poderes que la integran o al menos, 
si no toma la iniciativa, esté en condiciones de neutralizar las reivindicaciones contrarias al interés público o incluso más, pueda convertir la presión de los diferentes poderes enfrentados en un ejercicio de deliberación y cooperación entre ellos.

Si un gobierno local concebido desde el modelo ministerial tiene una eficacia muy dudosa en la definición de políticas y en la toma de decisiones, algo parecido ocurre en su capacidad de dirigir la administración. Tal como vemos en la segunda anécdota, la del arquitecto municipal polivalente, es una característica de los ayuntamientos de tamaño medio la inevitable transversalidad de las políticas, la necesidad de que casi todo el personal distribuya su tiempo en actuaciones temáticamente muy diversas.

Sería imposible económicamente organizar un ayuntamiento de tamaño medio desde una lógica divisional, con unidades totalmente independientes para cada temática local. Pero si la estructura política adopta la forma de multitud de responsables actuando cada uno a su aire es inevitable que muchos funcionarios deban compartimentar su atención hacia muchas actuaciones diversas. Ello hace que en la práctica los concejales se conviertan en unos pobres predicadores intentando que, por lástima o por misericordia, los funcionarios se ocupen de su tema particular. La consecuencia práctica es que de hecho son los funcionarios los que acaban decidiendo las verdaderas prioridades, y que es el ritmo y los objetivos de trabajo decididos de forma autogestionada por los funcionarios los que definen la agenda política, y no al revés.

\section{Proponemos un nuevo modelo de gobierno local}

El debate en torno a la gobernanza, el peso de las instituciones o la generación de capital social, giran en torno al liderazgo para alcanzar la confianza suficiente que promueva la cooperación entre todos los poderes de la red.

Parece obvio que un gobierno con la lógica del modelo ministerial tiene bajas capacidades para una gobernanza de calidad. Está concebido como una organización de rendimiento más apta en el despliegue de un incesante activismo municipal (hacer muchas cosas) que de una organización estratégica preparada para jerarquizar sus prioridades de acuerdo con criterios debatidos en el seno del equipo de gobierno.

Para que la gobernanza sea el objetivo del gobierno local es necesario terminar con la figura bienintencionada del concejal obsesionado por merecer el sueldo que se esfuerza en aprender urbanismo. Esto es un error. La formación de un gobernante no exige competencia profesional 0 , al menos, no es la más valiosa de las exigencias requeridas por la dirección política. Por ejemplo, en el caso del arquitecto municipal lo que debe estar claro es cuál de las tres políticas -el alumbrado de la calle, la remodelación del teatro o el informe para la licencia de obras- tiene preferencia. Ningún criterio experto decidirá el orden de prelación, será la oportunidad política la que aconseje la celeridad de una en detrimento de las otras dos. Pero para captar y aprovechar la oportunidad hay que estar preparado.

En este trabajo proponemos una forma distinta de organización del gobierno local superando la división en áreas y evitando las carencias del modelo ministerial. Intentamos pensar el gobierno local para promover la gobernanza y la articulación de la red.

Hacemos esta propuesta pensando en la calidad de la representación, en lo que G. SARTORI ${ }^{4}$ ha llamado la dimensión normativa de la representación, un ángulo apenas estudiado si se compara con la atención recibida por los aspectos empíricos y cuantitativos como el sistema electoral o la distribución social y territorial de los dirigentes políticos.

En lugar de la división habitual en áreas, planteamos el impulso de tres ejes:
a) Relación con la ciudadanía
b) Relaciones institucionales
c) Reflexión estratégica

a) Bajo el concepto genérico de ciudadanía englobamos, por un lado, todas aquellas reivindicaciones planteadas al gobierno local y, por otro, la comunicación del gobierno con la sociedad para explicar las políticas que se van a llevar a cabo o el balance de las terminadas. Es decir, la relación entre gobernantes y gobernados que abordada desde la perspectiva de la representación política equivale a lo que H. PINTKIN 5 llama controversia entre el mandato de los representados y la independencia de los representantes.

La corriente participacionista sostiene que el mandato obliga al representante a sujetar su actuación a las demandas ciudadanas, después de todo es un delegado sin autonomía para decidir sobre la mejor forma de satisfacer las expectativas de los representados. En cambio, los partidarios de la independencia sostienen la necesidad de un amplio margen de maniobra que permita al representante elegir en cada momento lo más conveniente para quienes representa. Planteada así la controversia incurre en una aporía irresoluble de la que sólo podemos escapar admitiendo y sobrellevando la ineliminable disputa entre ambos polos: un representante no puede desconocer lo que sus electores quieren pero no puede limitar su actuación a satisfacer sus deseos. Pocas definiciones de la política captan mejor este doble vínculo que la de Paul Valéry: 
"La política ha sido, durante siglos, el arte de impedir a los hombres que se mezclen en lo que les concierne: la política se ha convertido en el arte de interrogarlos acerca de lo que ignoran".

El gobierno local debe saber interrogar a sus ciudadanos, debe sentirse vinculado por sus demandas pero también ha de conseguir el cambio de las primeras preferencias. Éste es un verdadero ejercicio de liderazgo político que no se deriva de la superioridad del representante sobre el representado sino de la diferente posición que ocupan en el proceso político. Cuando un equipo de gobierno se encuentre ante una demanda que estime poco urgente o de menor prioridad estratégica tienen que explicar las razones de por qué la desecha, no hay que esperar a la campaña electoral, ha de aprovechar el revuelo que levanten eventuales minorías activas para impulsar una campaña de comunicación donde la gente pueda valorar la opción adoptada.

El contacto con la ciudadanía es fundamental. Como escribe H. PINTKIN, a diferencia del Derecho privado donde el mandatario da instrucciones concretas al mandante, el representante político no tiene un único principal sino una pluralidad de mandatarios cuyas reivindicaciones, varían a lo largo del tiempo como reacción a las propuestas políticas de los representantes. Éste es el sentido del marketing político que fracciona la población en diferentes segmentos para atender mejor las peticiones de cada uno.

Los miembros del equipo de gobierno dedicados a la relación con los ciudadanos deben estar apoyados por un gabinete de profesionales del marketing que identifiquen estos segmentos sociales y trabajen con ellos empleando la variada gama de técnicas de investigación social, desde el sondeo a los grupos de discusión.

b) Muchas de las decisiones claves para una ciudad son competencia de otros niveles de gobierno. Normalmente la relación con la diputación y el gobierno autonómico la lleva el alcalde pidiendo o exigiendo recursos para proyectos puntuales. Raramente el viaje de un concejal o de un alcalde a la diputación o a la consejería está precedido de una meditada estrategia del equipo de gobierno. Lo más probable es que, en la lógica del modelo ministerial, sea el empeño voluntarista de un miembro del equipo el único criterio cuando se acude a convencer a los otros gobiernos de la oportunidad de una política.

El área de relaciones institucionales es vital para gobernar la red porque es infrecuente que una política local no afecte a otros municipios o a competencias autonómicas o incluso a materias propias del ámbito estatal. Por meritorio que sea el esfuerzo para separar las competencias sobre una misma materia, el derecho no cancela la necesidad de unas relaciones intergubernamentales fluidas. El gobierno local no puede esperar a que la diputación o la comunidad autónoma contemplen alguna de sus políticas, ha de propiciar que estos gobiernos se vean en la necesidad de coo- perar o en caso contrario, quede claro el coste político que asumen por la negativa a la cooperación.

Cuesta poco trabajo ver la estrecha conexión entre el equipo de relación con los ciudadanos y el de relaciones institucionales. Una política que cuente con el apoyo de todos los actores locales y un amplio respaldo social tiene muchas más posibilidades de abrirse camino que otra que solo responda a la iniciativa de un concejal.

La gobernanza se define como la capacidad de gobierno, el liderazgo político para conseguir que organizaciones autónomas a las que no se puede obligar a colaborar, perciban la colaboración más ventajosa que la actuación en solitario. Este proceso de acercamiento y complementariedad no se produce de forma espontánea, tiene que ser inducido, articulado por los poderes públicos. Aunque la literatura sobre gobernanza insiste en la ausencia de jerarquía entre los plurales poderes de un territorio, también advierte de que la horizontalidad de las relaciones no reduce al estado, en nuestro caso al gobierno local, a un actor equiparable a una asociación de vecinos o a un grupo de empresarios.

Significa esta redefinición del lugar de los poderes públicos en las sociedades complejas que, si bien el gobierno pierde el monopolio de la iniciativa, conserva la facultad de dar término a un proceso político pronunciado la última palabra. Sirva esta afirmación para matizar las experiencias de planificación estratégica que convocan a toda la población en una multitudinaria asamblea que acuerda una infinidad de líneas estratégicas tan indefinidas y genéricas que no pasan de ser piadosos deseos.

Ubicarse en la red, articularla, exige del gobierno local una estrategia propia para no caer víctima de las estrategias ajenas. A estas alturas de la exposición ha de quedar claro que la concurrencia de estrategias constituye un indicador de riqueza política pero el buen gobierno local exige que el ayuntamiento disponga de un proyecto político para evaluar el resto de las estrategias.

c) Disponer de una estrategia supone acabar con el activismo municipal del modelo ministerial y conceder prioridad a la reflexión. Ningún miembro del equipo de gobierno debería descender a ocuparse de tareas que no requieran decidir entre al menos dos alternativas. Suele ocurrir en los ayuntamientos que se confunda la firma con el mando y los concejales tengan la tentación de firmar todos los documentos para evitar que los funcionarios les usurpen la dirección política.

Con esta mentalidad es imposible estar a la altura de una buena gobernanza. Hay medios suficientes para que un equipo de gobierno se asegure de que sus políticas no encuentren resistencia en la administración. Por lo tanto, alcalde y concejales deben concentrar sus esfuerzos en pensar. Hay que constituir un equipo de reflexión estratégica con aquellos concejales más ima- 
ginativos e innovadores para que las reuniones de la comisión de gobierno o del grupo municipal no tengan lugar a deshoras y en medio de la indiferencia de los asistentes.

La fuga del modelo ministerial en tantas organizaciones como concejalías encuentra en esta propuesta una nítida superación porque las tres áreas han de coordinar su trabajo.

\section{El modelo funcional de gobierno local}

El nuevo modelo de gobierno local que proponemos y que llamamos modelo funcional, por el énfasis en el desarrollo de las tres funciones de gobierno antes expuestas, debería permitir dar un salto desde la actual precariedad de la acción política local hacia la posibilidad, al menos, de la gobernanza local.
Ello ha de posibilitar también la mejora de la eficacia del gobierno local dirigiendo la administración. En este punto la salida es un modelo gerencial, un modelo ejecutivo. Pero cualquier sistema de gerencia del ayuntamiento fracasará si no se desarrolla a la vez un sistema de gobierno efectivo.

Hay autores que han percibido en el modelo gerencial la solución de todos los males del gobierno local, como si el único problema fuera la falta de ejecutividad. Pero el desarrollo de un modelo gerencial sin mejora del sistema de gobierno crearía un monstruo, un elefante con cerebro de mosquito.

No se puede concebir el gobierno local como una empresa en la que hay que encontrar un buen gerente y los políticos deben limitarse a pagarle, a aprobar sus propuestas y a aplaudirle. Esto es una utopía tecnocrática y antidemocrática. En los Ayuntamientos, un buen gerente sólo será posible con un buen gobierno que ejerza plenamente sus funciones.

\footnotetext{
* Abogado y Consultor de Estrategia Local

** Profesor en la Facultad de Ciencias Políticas y Sociología en la Universidad de Granada
}

${ }^{1}$ El Anteproyecto de Ley Básica de medidas para la racionalización y modernización de la Administración Local presenta la novedad de que el alcalde pueda designar y cesar libremente hasta la mitad de la Junta de Gobierno Local.

\footnotetext{
${ }^{2}$ La estructuración de las organizaciones, Ariel 1995

3 La lógica de la acción colectiva, Ed.Trillas 1992.

4 Teoría de la Democracia, vol.1, Alianza 1987.

5 El concepto de representación, Centro de Estudios Constitucionales, 1985.
} 